Reference in

\section{the Age of}

\section{Disinformation}

\section{Nicolette Warisse Sosulski and David A. Tyckoson}

Correspondence concerning this column should be directed to Nicolette Warisse Sosulski and David A. Tyckoson, e-mail: librista@gmail.com and davety@csufresno.edu.

\section{MEET SCYLLA AND CHARYBDIS: INFORMATION LITERACY IN CURRENT TIMES}

\section{Nicolette Warisse Sosulski}

It was my regular How to Be a (Re)Search Ninja class, a combination workshop I do once a month on search skills and information literacy. I was in the part about "websites you can trust," and my brain came to a screeching halt. This was a group that had been more involved and engaged than those in some offerings of the class, and I could tell that they were soaking in everything I could tell them. Usually at this point I talk about government websites- www.bls.gov, www.nih.gov, www.nlm.gov, www.medlineplus.gov, www noaa.gov, www.epa.gov, www.nps.gov, etc.—and how they can be a great source for pure, factual information. It was at this point that I froze.

The day after the 2017 inauguration, multiple topics had disappeared from www.whitehouse.gov. "Alternative facts" entered the White House press secretary lexicon on January 22, 2017. The National Park Service had been muted on Twitter the second week of January, suspiciously soon after inauguration attendance statistics had been released. President Donald Trump reportedly stopped the Environmental Protection Agency and the US Department of Agriculture from issuing press releases and posting on social media on January 24, 2017. A number of presidential appointments had been made that gave me great concern over the future of the continued information provision on those sites, and as it turned out, on October 20, 2017, an analysis came out in the New York Times showing that the Environmental Protection Agency had removed dozens of online resources dedicated to helping local governments address climate change. Thousands of scientists had marched on Washington on Earth Day, April 22, 2017, and this had expanded into a global phenomenon held in more than six hundred cities on six continents-and cheered on by scientists on a seventh, Antarctica.

My mind whirled. How was I to tell my patrons that government agencies and their websites were among the most dependable and stable sources of information that a citizen could consult? How could I say that indications were that things were looking bad in that regard if the events that I feared had not happened yet? How was I to do this in a stable, objective manner when I was aware that I was personally politically appalled and professionally aghast—and to a room that no doubt, given my library patron base's demonstrated election returns, contained at least a few people who 
were politically supportive of at least some of the agents of the very actions that hammered me as an information literacy professional? And these were students whom I might never have an opportunity to instruct in information literacy ever again.

The rest of that part of the presentation was not my best ever. The class, understandably, asked how this was different than any change of administration. I stated that the information on US gov sites had demonstrated itself to be more volatile this year than ever before, and that I personally had been taking note of postelection changes to government websites since I entered my MLIS program in 2002. I noted that I had never seen the number of changes that I had seen in the current administration, nor were previous administrations' changes as great in my considered opinion as an information professional. I told them about efforts such as the Environmental Data and Governance Initiative, a group working to track changes to science information availability, as well as numerous other information initiatives at the information policy institutes at American universities, who had worked feverishly the night before the election to download tens of thousands of science-related government web pages and hundreds of complete websites that they had identified as possibly under threat by the new administration, or of vital use to researchers, and to store them on servers outside the United States. I explained what the Internet Archive was and that they had stepped up efforts to mirror their content on servers in Canada prior to the inauguration. I reminded the group that scientists had never marched against an administration before. And I stated that there had been multiple statements by the newly elected president showing that he had thought for some time that one of the roles of the presidential office was to suppress and control information on the Internet-one of the earliest and most explicit of these occurring as far back as a campaign speech at the USS Yorktown back in December 2015:

So the press has to be responsible. They're not being responsible, because we are losing a lot of people because of the Internet. We have to do something. We have to go see Bill Gates and a lot of different people that really understand what is happening. We have to talk to them, maybe in certain areas, closing that Internet up in some way. Some of you will say, "Oh, freedom of speech, freedom of speech." These are foolish people. We have a lot of foolish people. We have a lot of foolish people. We have got to maybe do something with the Internet because they are recruiting by the thousands. ${ }^{1}$

My students were surprised, skeptical, concerned, and bewildered. They asked how they could possibly be sure of anything from then on. My response was, to my mind, unsatisfactory. I talked to them about checking multiple sources, about multiple political points of view, about looking for reasons that information might be biased. I then tried to continue with my class and the other parts of the lecture that were not so slippery.

Since then, the term "fake news" has shown up more and more often, seemingly every day. Statistics indicate that people are reacting by shutting down, giving little or no credence to anything that they hear that is "news." And I am still wrestling with how I and other librarians are to address what I view as an information crisis. Where does that leave our profession? I am looking to the authors of the pieces in this issue, as well as my co-editor, Dave Tyckoson, and Barry Trott, the editor of RUSQ, among many, to give counsel on this conundrum.

\section{LIBRARIES AND THE CHANGING INFORMATION LANDSCAPE-HOW DO WE RESPOND?}

\section{David A. Tyckoson}

As librarians, we are accustomed to dealing with trusted information sources. We acquire materials for our collections based on who wrote it, where it came from, what it is about, and sometimes what the reviewers say about it. We acquire materials covering a wide range of viewpoints, but each source within those viewpoints is selected by one of us. Over time, we create a collection that is truly fair and balanced.

Yet user faith in information has been shaken. People do not know which sources to trust and often do not know how to evaluate the information that they receive. Some people reject information that disagrees with their personal views, even when that information comes from reputable sources. This creates a credibility problem that we librarians need to address.

The publishing world is very different today than it was only a few decades ago. Half a century ago, news and information was fairly simple. Libraries dealt with one format: print. The sources that we purchased all went through a process that vetted the content that they contained. Books were published primarily by commercial publishers. The books that they published were written by authors commissioned based on their expertise. Their content was edited by people employed by the publisher who checked the factual content and made the writing better. Only when the content was deemed ready for the reader-and commercially viablewas a book published.

A similar process existed for magazines and newspapers. Reporters and writers submitted content to their editors. Those editors reviewed, corrected, and usually shortened the articles to fit the available space. Only articles approved by the editors made it into print in the magazine or newspaper. This editorial review process ensured a certain level of factual quality of the articles that were published, allowing the public to trust the content.

Similar review techniques were available for scholarly sources. Academic and scholarly journals used the 
peer-review process to identify the best research content. Only those papers that passed the peer-review process would appear in print in the journal. Researchers could be confident that the articles were vetted by experts, giving them confidence in the results that they were reading - and citing.

All of these processes resulted in a public that trusted the information sources that they read. They knew that some sources were less credible than others-such as the National Enquirer - but they generally had faith in what they read on a regular basis. The public understood and believed the news and articles that were part of their daily lives.

Librarians working with limited budgets would select the books, magazines, and newspapers that best matched the needs and interests of the local community. A number of methods were created to assist us in the selection process, including reviewing journals and approval plans. Library collections were built almost entirely on mainstream publications that librarians considered the best content available. Because of the diligence of librarians, collection content was reliable, authoritative, and as comprehensive as the budget would allow.

The reliance of libraries on commercial publishing was far from a perfect method of building collections. Since mainstream publishing is exactly that, voices outside that mainstream would often be excluded from library collections. Minority ideas-whether political, social, linguistic, or geographical-were often excluded from mainstream commercial publishing and thus were often excluded from many library collections. Librarians made efforts to include as much as possible from as wide an array of sources as possible, but the ease of purchasing from commercial publishers placed their works in most library collections.

People in the community came to the library because that is where the information was. The library had many more books, magazines, and journals than any individual could afford, and so people came to the library to read, check out, and use the information in the library. And people trusted what they found in library collections. Since the works in the collection were created by authors and editors and selected by librarians, they had a high degree of credibility. If you found it in a book at the library, you believed it.

Interestingly, while libraries carried local and national newspapers, libraries were rarely sources for current news. Most people received news through personal subscriptions to a local newspaper-and through broadcast media. In particular, the three national television networks provided Americans with national and international news every evening. For the first time, those news reports included video, allowing viewers to see the places, events, and people being covered. They were also ephemeral, since they could not be saved or recorded. People watched the news at home on television, but they researched the news in print at the library. However, they certainly trusted and believed what they saw and heard on the news. In 1976, Walter Cronkite was named the most trusted man in America by U.S. News and World Report, even though all Cronkite did was read the news on television.
No one thought that mainstream reporting-whether in the newspaper or on television-was misleading them. People consumed, trusted, and believed that what the media told them was factually correct. Sometimes stories turned out to be incorrect, but that was definitely the exception and not the rule. People got into the habit of believing what they saw on television or read in the newspaper. That was the norm for many, many decades.

Fast forward to today, where the news and information environment has changed dramatically. Newspapers are on their death bed, continually losing readership and advertising revenues. Local television news still survives but has tremendous competition from the wealth of cable and online channels. And people's faith in content seems to be at an alltime low. How did we get to this point?

Several distinct and interrelated factors have changed the average citizen's relationship with the media. The first is abundance. There are so many news and information outlets available today that we are overwhelmed by the sheer number of choices. With hundreds of television channels and thousands-or maybe hundreds of thousands-of Internet channels, people can choose from more sources than ever before. And with that many channels, each one seeks to find its own place in the information ecosystem. As a result, we have very specialized and focused media outlets, which means that anyone can find a channel that matches their own interests and beliefs. Are you a gay conservative Republican? Check out logcabin.org. A Southern anarchist? Actualanarchy.com is written for you. An Armenian American activist? Anca.org will be of great interest. A Bernie Sanders-supporting far-left socialist? Then you certainly read jacobinmag.org. And if you are a Hillary Clinton supporter who believes in UFOs, then you certainly must have read this story: https://www.huffing tonpost.com/entry/hillary-clinton-vows-to-investigate-ufos _us_5687073ce4b014efe0da95db. There is so much information on the Internet that anyone can find something that matches their personal interest, no matter what that interest may be.

With such a huge number of sources covering every imaginable angle of every possible story, it is no wonder that people are overwhelmed. With so much information instantly available to them, people do not know how to separate them from each other. People are drowning in an abundance of information that reaches far beyond that available at any other time in history. And as a result, they do not know where to turn to get the information that they used to trust.

One reason for such an abundance is that everyone can now be an author. Write a story, put it on a web page or release it on social media, and you may become the next Daniel Ellsberg, Gary Vaynerchuk, or Liza Koshy. All it takes is to get your story included in standard tools such as a Google search, and people will find that story. And if you write well enough and sound credible- and maybe even if you do not-people will read it. And depending on what you say and how you say it, you might become famous. 
A second factor leading to our current information confusion is the speed at which information is distributed. Our technology is so good and so fast that information uploaded an instant ago is available right now. Stories that once took a day to write and edit (for newspapers), several weeks or months to produce (for magazines and journals), or years to create (for books) now cross the web literally at the speed of light. Information posted right now can be shared, commented on, and reproduced within seconds. Without the quality control of the editorial process, incorrect information, misinformation, and even fraudulent information can become accepted by some people in a very short period of time. And if someone influential shares that information, it becomes accepted fact among that person's followers.

In addition, easy access to multimedia results in the availability of video, audio, and other formats. YouTube allows anyone to record and post their videos. When an event occurs-from a natural disaster to a sporting event to a concert, a crime, or a birth - the world can see it while it is happening, sometimes from multiple viewpoints or perspectives. The speed at which information is distributed creates an expectation that all information will be available while it is happening. And there is no process to authenticate that information, which makes all information seem equally valid.

The third factor leading to our current information confusion is segmentation. One of the impacts of social media is that it easily groups people along ideological lines. If I like cat videos and see a good cat video on social media, I can follow the person who put it online in hopes of getting access to more cat videos. I can also see who else follows that video, which helps me identify other people who watch cat videos. And I can share the video on my social media platform so that my followers will also get the opportunity to watch it. I can join a cat video fan group where I will find lots of other videos-and other cat video fans. Within a short period of time, cat video fans are linked together so that they all see new cat videos whenever anyone posts one.

We can also discuss the qualities of various videos, stating our preferences for others to comment on. Subgroups can form, such as fans of yellow tabby cats, Siamese cats, or-my favorite-black cats. Variations get spun off, like sleeping cat videos or audio recordings of purring cats. The people who identify with any or all of these concepts quickly get connected with each other and are able to show their videos, comment on other people's videos, and express their likes and dislikes. People join and leave the group based on their interests and capacity for dealing with cat videos and cat video commentators. An occasional dog video fan will join to promote the advantages of canines over felines-and most of the group will want that dog fan kicked out. Some people will dominate the conversation, some will get nasty when they do not like a video, and others will become the primary suppliers of new videos. A few will became cat video spokespersons, and one or two will become cat video superstars. Most people in the group will not post or say much, but they all will watch the videos and follow the discussions.

Cat video likes and dislikes are not going to have much impact on the larger world, but groups formed around other topics will have an impact-and this is where group segmentation really changes how people interact with each other. Most people would rather be right than wrong - and one way to be right is to hang out with others who tend to agree with you. We all join groups that match our own personal preferences and interests. We follow the discussions of those groups and maybe even contribute to them. If we join a group that turns out not to match our interests, we drop out and join something else. The result of this practice is to create thousands of interest groups in which people talk only to those with whom they agree. Over time, that agreement becomes the norm, creating a world view in which whatever the group supports is what seems to be what everyone else supports. In extreme cases, the group becomes the world in which its members live.

The segmentation of people into narrow subdivisions of society is one problem that we face, but certainly not the only one. Today, some people in positions of influence and power-up to and including the president of the United States-are attacking published information and, indirectly, the system that creates that information. By stating that news reports are "fake," they cause the public to doubt the validity of information sources that they had previously trusted. Once doubt is established, it undermines the entire system of news and information-which is exactly the intent of those claiming that news that they do not approve of is "fake."

A related and far more significant problem is the intentional distribution of false news stories. These stories, including some that are obviously outrageous_-such as the one about a Hillary Clinton child sex ring operating out of a Washington, DC, pizza parlor-have an impact on the public. At best, they clutter the daily information cycle with worthless news that people must filter out. At worst, they influence people and lead to actions or decisions arising from misinformation. Whether or not Russian operatives attempted to influence the 2016 US presidential election, the distribution of false information on both candidates clearly caused some voters to change their minds.

All of these issues are causing the public to lose faith in the information that they receive on a daily basis. The problem of enormous quantities of information spreading rapidly, increased segmentation of society, and deliberately false sources can make it difficult for those of us who make a living in the information world, including librarians. What can we do to help people in our communities make sense of this bizarre information environment?

Libraries and librarians can indeed help people make sense of what is going on today. We have four advantages that place us in a strong position to take on this task:

- Libraries are trusted institutions. People see libraries as sources that they trust to provide valid information. Our 


\section{A REFERENCE FOR THAT}

long tradition of building collections of reliable resources that cover a wide range of opinions has created an environment where people believe that libraries will provide credible information. The August 2017 Pew Research Center report indicates that 78 percent of adults, including 87 percent of millennials, feel that public libraries help them find information that is trustworthy and reliable. With that level of trust from our communities, we start in a position of strength to confront this problem. We can build on that trust to help improve the communities that we live in.

- Librarians are leaders in teaching information literacy. For decades, librarians have helped teach people how to evaluate information. Academic librarians teach students in information literacy classes. Public librarians teach community members in workshops. All librarians teach the people who ask questions at their reference desks. These skills are needed more than ever right now-and librarians can still be the people to promote them. With our involvement, more people will learn to evaluate what they find and to select quality information over fake information. The public is aware of the problem and does not like being deceived. Librarians can play a role in educating our communities to be more informed information consumers.

- Libraries are places of inclusion. Everyone is welcome in libraries. We help anyone who comes through our doors and our websites, regardless of whether they are members of our primary community or not. We provide assistance and information to all-usually without an appointment and always without charging any direct cost. This makes libraries the rarest of institutions in today's society-places that are open and welcoming for everyone. We help people understand what is going on in the world, from students working on projects to adults seeking financial information to the UFO enthusiast trying to find the truth that must be out there. We do this with respect for the privacy of each individual and with the skills that make us librarians. The trust that Pew identified in libraries is a natural result of the way that we conduct our daily business-and something that we can maintain through today's crazy information times.

- Libraries build collections of authenticated information. People still come to us to find valid and authenticated information, whether that information is in the form of books, journals, or electronic sources. Many of the issues related to fake news arise from ephemeral or unknown sources that get spread around the Internet without critical thinking. Library sources have undergone editorial processes that validate their content. We will never be as fast as Facebook at gathering information, but what we do gather has a much higher level of credibility. Libraries build collections for the long term, not the moment-and those collections have long-term impact. By continuing to build strong, authenticated, accurate collections, we are creating the foundation for future generations to deal with this same problem.

We are living at a very interesting point in the history of information production and delivery. Confusion reigns and credibility has fallen to an all-time low. Some people only want the information that they believe is true and that will support conclusions that they have already made. Those people rarely change their beliefs and do not really want help-just support. Librarians can help them find that kind of information, but we cannot change their beliefs. Fortunately, these are not the majority of people in most of our communities. We can help the majority by providing them with authenticated information sources, teaching them how to find and evaluate information, and welcoming them into our environment, no matter who they are. In other words, we can help them by being the librarians that we always have been and always will be. And the world needs us now more than ever before.

\section{Reference}

1. Donald Trump, campaign rally speech at USS Yorktown, CSPAN broadcast, December 8, 2015, https://www.c-span.org /video/?401762-1/presidential-candidate-donald-trump-rally -mount-pleasant-south-carolina. 